$16^{\circ}$ USIHC - Congresso Internacional de Ergonomia e Usabilidade de

\title{
GAMIFICAÇÃO E INTERDISCIPLINARIDADE: UMA NOVA PERSPECTIVA METODOLÓGICA PARA O ENSINO NA ÁREA DE MODA
}

\author{
GAMIFICATION AND INTERDISCIPLINARITY: A NEW \\ METHODOLOGICAL PERSPECTIVE FOR EDUCATION IN THE \\ FASHION AREA
}

\author{
Andréia Mesacasa ${ }^{1}$, M.Sc \\ Camila Carmona Dias², M.Sc
}

(1) Instituto Federal de Educação, Ciência e Tecnologia do Rio Grande do Sul (IFRS) e-mail: andreiamesacasa@hotmail.com

(2) Instituto Federal de Educação, Ciência e Tecnologia do Rio Grande do Sul (IFRS) e-mail: camila.dias@erechim.ifrs.edu.br

Interdisciplinaridade, Gamificação, Moda

\begin{abstract}
O presente estudo tem como objetivo a apresentação de uma proposta metodológica fundamentada na interdisciplinaridade fazendo uso da gamificação. Esta proposta integrará a disciplina de Projeto Interdisciplinar I, pertencente ao Curso Técnico Concomitante em Produção de Moda do Instituto Federal do Rio Grande do Sul, campus Erechim. Composta por três fases, a proposta objetiva o cumprimento de um desafio específico da área de Produção de Moda, sendo que em cada uma das fases são ofertados meios para proporcionar o cumprimento de parte do desafio. Sob este aspecto, a gamificação da referida disciplina será uma experiência inovadora e poderá ser consolidada como uma nova perspectiva metodológica para o ensino na área da moda.
\end{abstract}

\section{Interdisciplinarity, Gamification, Fashion}

The present study aims to present a methodological proposal based on interdisciplinarity making use of gamification. This proposal will integrate the discipline of Interdisciplinary Project I, belonging to the Concomitant Technical Course in Fashion Styling of the Federal Institute of Rio Grande do Sul, Erechim campus. Composed of three phases, the proposal aims to fulfill a specific challenge of the Fashion Styling area, and in each of the phases are offered means to provide the fulfillment of part of the challenge. In this regard, the gamification of said subject will be an innovative experience and can be consolidated as a new methodological perspective for teaching in the field of fashion.

\section{Introdução}

Este estudo tem como objetivo a apresentação de uma proposta metodológica fundamentada na interdisciplinaridade fazendo uso da gamificação. Esta proposta integrará a disciplina de Projeto Interdisciplinar I, pertencente ao Curso Técnico 


\section{$16^{\circ}$ \\ ERGODESIGN USIHC CINAHPA}

$16^{\circ}$ Ergodesign - Congresso Internacional de Ergonomia e Usabilidade de Interfaces Humano Tecnológica: Produto, Informações Ambientes Construídos e Transporte

$16^{\circ}$ USIHC - Congresso Internacional de Ergonomia e Usabilidade de Interfaces Humano Computador

CINAHPA | 2017 - Congresso Internacional de Ambientes Hipermídia para Aprendizagem.
Concomitante em Produção de Moda do Instituto Federal do Rio Grande do Sul, campus Erechim. O currículo do curso se desenvolve em um processo contínuo, com atividades voltadas à interdisciplinaridade evidenciada por meio dos Projetos Interdisciplinares que integram cada um dos quatro semestres letivos durante os quais o curso acontece. Neste sentido, com o intuito de emprestar maior dinamicidade às aulas e motivar os discentes à participação ativa durante as aulas, optou-se pela elaboração desta proposta seguindo a sistemática dos jogos. A mesma corresponde a três fases: 1. Conhecimento: A Pesquisa é a chave, 2. Ferramentas e Métodos: Quem sabe cria, e 3. A Jornada: Um passo de cada vez. Cada uma das fases está alinhada a elementos e mecânicas próprios da sistemática dos jogos, tendo como objetivo comum cumprir o desafio de "Criar cenários para execução de fotos de moda, tendo como base um período da história e um filme que remeta à época". As fotos deverão ser compostas por looks que utilizem vestimentas atuais e que tenham relação com a época abordada. Para tanto, em cada uma das fases serão ofertados meios para proporcionar o cumprimento de parte do desafio. Para melhor compreensão, ao longo deste estudo, serão abordadas a contextualização do curso, a ênfase na interdisciplinaridade e as premissas da gamificação, que culminam na proposição de uma nova perspectiva metodológica de ensino.

\section{Fundamentação Teórica}

\subsection{O Curso Técnico Concomitante em Produção de Moda: Contextualização}

Os Institutos Federais, estruturados a partir do potencial dos CEFETs, das Escolas Técnicas e Agrotécnicas Federais, foram criados pela Lei $\mathrm{n}^{\circ}$ 11.892, de 29 de dezembro de 2008, a qual estabeleceu, no âmbito do sistema federal de ensino, a Rede Federal de Educação Profissional, Científica e Tecnológica, da qual os institutos fazem parte.

Atualmente, todos os estados brasileiros possuem no mínimo um Instituto Federal. No Rio Grande do Sul existem três IFs, sendo eles: o Instituto Federal Farroupilha, o Instituto Federal Sul-Rio-
Grandense, e o Instituto Federal do Rio Grande do Sul [SILVA, 2009].

O IFRS possui atualmente 17 campi distribuídos pelo Estado entre eles está o Campus Erechim. O Campus Erechim iniciou, efetivamente, suas atividades em novembro de 2009 , oferecendo cursos técnicos, na modalidade subsequente, e, posteriormente, em nível superior. Em 2016, o Campus Erechim passou a ofertar cursos na modalidade concomitante ao Ensino Médio, sendo que um deles trata-se do Técnico em Produção de Moda [IFRS, 2016].

O Curso Técnico em Produção de Moda do IFRS, no catálogo de Cursos Técnicos do MEC, encontra-se no eixo tecnológico de Produção Cultural e Design. O curso possui como objetivo geral "formar profissionais com capacidade reflexiva para desenvolver propostas inovadoras voltadas à divulgação de moda, estabelecendo uma relação entre produto e consumidor por meio da produção de visual merchandising, imagem e publicidade de moda, além de eventos de moda, pautando-se em uma postura ética e de responsabilidade social" [IFRS, 2016, p.23]. O Curso está estruturado em quatro eixos principais, quais sejam: (I) Pesquisa e Criação de Imagem de Moda, (II) Produção de Visual Merchandising, (III) Produção de Publicidade de Moda e (IV) Produção de Eventos de Moda. A Matriz Curricular do Curso de forma articulada ao ensino médio, contempla novecentas e setenta e duas horas, a serem integralizadas em quatro semestres letivos, atendendo os objetivos propostos para a formação do Técnico em Produção de Moda.

O currículo do curso evidencia um processo contínuo, que envolve atividades voltadas à interdisciplinaridade, práticas laboratoriais e também de pesquisa, para desse modo vincular os pressupostos teóricos e metodológicos aos princípios práticos, estabelecendo uma relação efetiva para a construção do conhecimento [IFRS, 2016].

Sob essa perspectiva, os projetos interdisciplinares integram o itinerário formativo do educando, pois visam ao aprendizado de competências próprias da atividade profissional e à contextualização curricular. Os Projetos Interdisciplinares I, II, III e IV são realizados, respectivamente, no primeiro,
Realização:
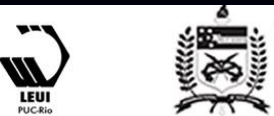


\section{$16^{\circ}$ \\ ERGODESIGN USIHC CINAHPA}

$16^{\circ}$ Ergodesign - Congresso Internacional de Ergonomia e Usabilidade de Interfaces Humano Tecnológica: Produto, Informações Ambientes Construídos e Transporte

$16^{\circ}$ USIHC - Congresso Internacional de Ergonomia e Usabilidade de Interfaces Humano Computador

CINAHPA | 2017 - Congresso Internacional de Ambientes Hipermídia para Aprendizagem. segundo, terceiro e quarto semestres do curso, contemplando temas como: Pesquisa e Criação de Imagem de Moda, Produção de Visual Merchandising, Produção de Publicidade de Moda e Produção de Eventos de Moda. Sendo assim, a organização curricular torna-se dinâmica e flexível, possibilitando novos modos e ritmos de acesso e apropriação do conhecimento e atendendo às necessidades e peculiaridades do mundo do trabalho, fundamentada primordialmente na interdisciplinaridade.

\subsection{A Interdisciplinaridade}

As teorias interdisciplinares se formalizaram durante a década de setenta. Surgiram pela necessidade de dar uma resposta à fragmentação dos saberes oriunda de uma vertente positivista. No Brasil, o conceito interdisciplinar foi introduzido por Japiassu [1976] e Fazenda [1991]. Ambos consideram que a abordagem disciplinar deve ser superada por meio das práticas interdisciplinares, assim concentram suas análises na necessidade de abertura do diálogo entre as áreas e disciplinas.

Dessa maneira, o termo interdisciplinaridade passa a ser utilizado por expressar um enfoque que se caracteriza por buscar

algo mais do que a justaposição das contribuições de diversas disciplinas sobre o mesmo assunto, e se esforça por estabelecer um diálogo enriquecedor entre especialistas de diversas áreas científicas sobre uma determinada temática. [ASSMANN, 1998, p. 162]

Na ciência Moderna, "o conhecimento avança por meio da especialização, pois ela está assentada na divisão e classificação do conhecimento para então determinar relações sistemáticas entre o que separou" [SANTOS, 1998, p. 64]. Assim, a crescente especialização, gerada pelos processos adotados para a produção dos novos avanços na ciência e na tecnologia, culminou numa fragmentação do corpus epistemológico. O excesso de especialização leva a um racionalismo que deforma a natureza e desumaniza o homem [GUSDORF apud JAPIASSU, 1976]. Entretanto, a pós-modernidade contrapõe-se a lógica da fragmentação fundamentada na especialização, "pois vê na disciplinarização um limite à reflexão, reprimindo e limitando os profissionais" [SANTOS, 1998, p. 64]. Dessa forma, a pós-modernidade traz o conceito de interdisciplinar como uma nova forma de organização do conhecimento e dos processos pedagógicos. Posto isso, afirma-se que tal conceito propõe uma nova ordem para o horizonte epistemológico, garantindo a construção de um conhecimento globalizante baseado em atitude de busca, envolvimento, compromisso, reciprocidade, rompendo assim, com as fronteiras das disciplinas [INSTITUTO PAULO FREIRE, 2011]. Contudo, salienta-se que esta nova forma de organização não exclui a disciplina como forma de organização do conhecimento. Pelo contrário, a interdisciplinaridade busca uma interação e integração, sempre que possível, entre as disciplinas. Tal ideia vem ao encontro da conceituação construída por Fazenda que explica que a interdisciplinaridade é a

[...] interação existente entre duas ou mais disciplinas. Essa interação pode ir da simples comunicação de ideias à interação mútua dos conceitos diretores da epistemologia, da terminologia, da metodologia, dos procedimentos, dos dados da organização referentes ao ensino e a pesquisa. Um grupo interdisciplinar compõe-se de pessoas que receberam sua formação em diferentes domínios do conhecimento (disciplinas) com seus métodos, conceitos, dados e termos próprios. [FAZENDA, 1979, p.27]

Ou seja, a interdisciplinaridade expressa a reciprocidade nas trocas entre as disciplinas que participam do processo. "A integração caminha para uma interação que inicia o processo interdisciplinar" [JAPIASSU, 1976, p.74]. A interdisciplinaridade, ainda hoje, é tema de discussão em vários países graças à urgência de sua aplicação, mas segundo Fontoura [2011], também se tem recusado muito as exigências interdisciplinares. Esse paradoxo é devido à ainda crescente especialização e visão cartesiana das ciências que ocupam o território do saber. Infere-se assim, que para a real efetivação da interdisciplinaridade "é necessário desenvolver a aptidão natural do espírito humano para situar todas essas informações em um contexto e um conjunto". Ou seja, é preciso construir métodos que permitam criar "as relações mútuas e as influências recíprocas entre as partes e o todo em um mundo complexo" [MORIN, 2001, p.14]. E
Realização:
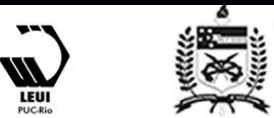


\section{$16^{\circ}$ \\ ERGODESIGN USIHC CINAHPA}

$16^{\circ}$ Ergodesign - Congresso Internacional de Ergonomia e Usabilidade de Interfaces Humano Tecnológica: Produto, Informações Ambientes Construídos e Transporte

$16^{\circ}$ USIHC - Congresso Internacional de Ergonomia e Usabilidade de Interfaces Humano Computador

CINAHPA | 2017 - Congresso Internacional de Ambientes Hipermídia para Aprendizagem. para que isso aconteça é necessário uma tomada de consciência e uma mudança de atitude diante do processo educacional.

Para o trabalho interdisciplinar são essenciais: a curiosidade, a abertura para o novo, o sentido de aventura e de busca e o uso da intuição. Adotar uma atitude interdisciplinar não significa recusar por completo o especialismo, mas sim, o dogmatismo dos saberes por ele estabelecido. O questionamento dos conhecimentos passa a ser uma constante sob este ponto de vista [FONTOURA, 2011, 91].

No campo da educação a interdisciplinaridade, além de ser posta como uma possibilidade entre tantas outras para a resolução de problemas, se apresenta como uma nova abordagem metodológica que traz novas propostas de trabalho.

\subsection{Gamificação}

Da evolução dos tabuleiros ao universo digital, os jogos fazem parte da história da humanidade. Para Huizinga "é no jogo e pelo jogo que a civilização surge e se desenvolve" [HUIZINGA, 1990, prefácio]. Dentro deste contexto, jogo pode ser definido como:

Atividade livre, conscientemente tomada como 'não-séria' e exterior à vida habitual, mas ao mesmo tempo capaz de absorver o jogador de maneira intensa e total. É uma atividade desligada de todo e qualquer interesse material, com a qual não se pode obter qualquer lucro, praticada dentro dos limites espaciais e temporais próprios, segundo uma certa ordem e certas regras [HUIZINGA, 1990, p.16].

De acordo com Tonéis [2015], em 1970, Clark Abt escreveu o livro Serious Games indicando as possibilidades de se criar jogos digitais com propósitos para além da diversão. Desse modo, os jogos sérios rompem com o conceito de jogo como atividade livre, assumindo um novo conceito de jogo como forma de treinamento ou avaliação de conhecimentos ou habilidades. Para Tonéis [2015], Abt (1987) considerou a diversão como um fator de grande importância nos jogos sérios, uma vez que o apelo emocional é o principal atrativo para este tipo de atividade.

Dentro deste contexto, destaca-se a gamificação. Segundo Kapp [2012], gamificação é a utilização do pensamento dos jogos, bem como das mecânicas e estéticas baseadas em jogos para envolver as pessoas, motivar a ação, promover o aprendizado e resolver problemas.

Fardo [2013] descreve a gamificação como sendo o uso, fora do contexto dos jogos, dos elementos que compõem os jogos a fim de buscar a motivação e o envolvimento encontrados em jogadores quando interagem com bons jogos. Ainda de acordo com Fardo [2013],

A gamificação se apresenta como um fenômeno emergente com muitas potencialidades de aplicação em diversos campos da atividade humana, pois a linguagem e metodologia dos games são bastante populares, eficazes na resolução de problemas (pelo menos nos mundos virtuais) e aceitas naturalmente pelas atuais gerações que cresceram interagindo com esse tipo de entretenimento. Ou seja, a gamificação se justifica a partir de uma perspectiva sociocultural [FARDO, 2013, p. 1].

Entretanto, a gamificação não se constitui como uma tentativa para transformar a aprendizagem em um jogo, mas para entender em que circunstâncias "elementos de jogo podem orientar o comportamento em situações de aprendizagem" [LEE e HAMMER, 2011, p.2]. Para os autores, o uso da gamificação pode deixar as regras mais leves, além de proporcionar diferentes experiências emocionais. Desse modo, uma sala de aula pode se tornar um ambiente gamificado ao apropriar-se da ludicidade e da dinamicidade dos jogos, estimulando o aprendizado autônomo e divertido. De acordo com Seixas [2014], pesquisas a respeito da utilização dos games na educação tem evidenciado resultados positivos com relação à experiência de aprendizagem, bem como relatam melhorias significativas na motivação e, consequentemente, no engajamento.

Para Corti [2006], o desenvolvimento de novas estratégias de aprendizagem e paradigmas de interatividade, a aprendizagem reflexiva e crítica, a aprendizagem pela exploração/descoberta, bem como o aumento da criatividade, capacidade de planificação e pensamento estratégico são alguns pontos que emergem da utilização dos games $e$ que podem auxiliar na educação.

\subsubsection{Gamificação: elementos e mecânicas}

Gamificar algo é usar mecânicas, estéticas e características dos jogos para envolver e motivar as pessoas a aprender e a resolver problemas. $\mathrm{O}$ processo de gamificação pode ser entendido como
Realização:
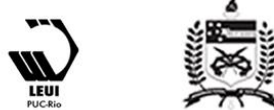


\section{$16^{\circ}$ \\ ERGODESIGN USIHC CINAHPA}

$16^{\circ}$ Ergodesign - Congresso Internacional de Ergonomia e Usabilidade de Interfaces Humano Tecnológica: Produto, Informações Ambientes Construídos e Transporte

$16^{\circ}$ USIHC - Congresso Internacional de Ergonomia e Usabilidade de Interfaces Humano Computador

CINAHPA | 2017 - Congresso Internacional de Ambientes Hipermídia para Aprendizagem. um compartilhamento de elementos do design dos jogos para atingir propósitos em comum, por exemplo, lançar desafios, usar estratégias, obter pontos para atingir objetivos claros, obter acessos restritos a itens bloqueados por meio de ações e estratégias para conquistar espaço ou etapas, ganhar visibilidade e recompensas, medalhas, prêmios por atividades cumpridas [BUNCHBALL, 2010].

Os elementos e as mecânicas dos jogos fornecem subsídios para que, a partir deles, seja possível criar um jogo que apoie determinado processo, ou simplesmente inserir elementos dos jogos no processo sem sequer chegar a se utilizar um jogo de fato [FARDO, 2013].

Para McGonigal [2012], os jogos apresentam quatro elementos fundamentais: objetivo, regras, sistema de feedback e participação voluntária. Segundo ela, objetivo é o que os jogadores trabalham para alcançar e fornece um "senso de propósito" para o jogo. As regras colocam limitações em como os jogadores podem alcançar esse objetivo, o que libera a criatividade e motiva o pensamento estratégico. O sistema de feedback fornece uma visualização aos jogadores de qual é o seu estado perante o objetivo do jogo e a participação voluntária requer que todos que estejam jogando aceitem essas regras, objetivos e feedbacks.

Já em relação às mecânicas dos jogos, Bunchball [2010] afirma que as mais comuns consistem em:

a) Pontos: São usados para recompensar os usuários através de múltiplas dimensões e diferentes categorias. Também podem ser usados para estimular a participação dos usuários.

b) Níveis: indicam o cumprimento de uma meta pelo usuário, quanto mais alto o nível atingido, maiores serão o respeito e status adquiridos.

c) Desafios, Troféus, Emblemas/Medalhas, Conquistas: Os desafios representam missões para que os usuários realizem a fim de atribui recompensas pela sua execução. Troféus, emblemas ou medalhas são o reconhecimento visível de que o usuário atingiu novos níveis ou concluiu desafios. d) Bens Virtuais: São objetos não-físicos, intangíveis que podem ser adquiridos utilizando os pontos que os usuários vão recebendo ao longo do tempo. É uma forma de incentivá-los a ganhar mais pontos bem como personalizar algo que reflete a sua identidade.

e) Placar de classificação, Ranking, Tabela de Pontuação: Indicam o posicionamento dos usuários em relação aos demais. São tabelas utilizadas para gerenciar e exibir a pontuação dos usuários com o objetivo de usar a competição como motivador do comportamento.

f) Competição: Permite aos usuários desafiar uns aos outros para obter a pontuação mais alta ou realizar determinadas atividades.

g) Recompensa: A recompensa, tangível ou intangível, é apresentada após a ocorrência de uma ação, com a intenção de que esse comportamento ocorra novamente.

\section{A proposta e suas fases de aplicação}

As disciplinas e respectivas ementas que compõe o primeiro semestre do Curso Técnico Concomitante em Produção de Moda são as seguintes:

a) História da Moda: A moda como fenômeno histórico, cultural e social. Movimentos socioculturais e psicossociais aplicados à indumentária. História da arte, da moda e sua relação com os contextos sociais, econômicos e políticos, da pré-história até a contemporaneidade. História e cultura afro-brasileira, africana e indígena com ênfase na moda. Direitos Humanos relacionados à construção social da moda.

b) Processos Criativos: Criatividade: conceitos, técnicas e ferramentas. O pensamento criativo. Criatividade e inovação. Processos criativos aplicáveis à produção de moda.

c) Composição de Imagem de Moda: Comunicação visual: princípios e elementos. Processos de composição de imagens de moda. Composições visuais conceituais e comerciais associadas à produção de moda.
Realização:

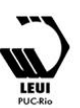




\section{$16^{\circ}$ \\ ERGODESIGN USIHC CINAHPA}

d) Projeto Interdisciplinar I: Atividade interdisciplinar: desenvolvimento de projeto e execução de pesquisa e criação de imagem de moda em todos os seus aspectos.

A disciplina de Projeto Interdisciplinar I é ministrada conjuntamente por todos os professores que atuam no referido semestre. Seu objetivo geral consiste no desenvolvimento de atividades voltadas à interdisciplinaridade dos conhecimentos e integração dos conteúdos referentes à Pesquisa e Criação de Imagem de Moda, estabelecendo uma relação efetiva para a construção do conhecimento técnico e científico do profissional. Neste sentido, tendo em vista a composição das turmas, constituídas em sua maioria por adolescentes, público este que demanda uma maior interação com os conteúdos a serem ministrados, bem como o intuito de atender ao objetivo proposto na disciplina, foi elaborada uma proposta de trabalho que segue a sistemática da gamificação. A proposta foi elaborada no formato de um desafio composto por três fases a serem cumpridas ao longo do semestre letivo. Segue o desafio: "Tendo como base um período da história e um filme que remeta à época, os alunos deverão criar um cenário para execução de fotos. As fotos deverão ser compostas por looks que utilizem vestimentas atuais e que tenham relação com a época abordada".

\subsection{Fase preliminar de preparação}

$\mathrm{Na}$ fase preliminar a proposta será comunicada aos discentes, bem como serão formadas as equipes e sorteadas as épocas históricas e seus respectivos filmes. Nesta fase, cada uma das equipes deverá elaborar um mapa mental contendo as características de seus componentes, bem como um painel iconográfico contendo estas mesmas características. Tendo como base o mapa mental e o painel iconográfico, cada equipe criará um símbolo a ser utilizado como elemento de identificação ao longo do desafio do semestre.

\subsection{Fase 1: Conhecimento: a pesquisa é a chave!}

Envolverá as atividades de elaboração de bancos de imagens e pesquisas históricas tendo como base filmes de épocas históricas específicas. $16^{\circ}$ Ergodesign - Congresso Internacional de Ergonomia e Usabilidade de Interfaces Humano Tecnológica: Produto, Informações Ambientes Construídos e Transporte

$16^{\circ}$ USIHC - Congresso Internacional de Ergonomia e Usabilidade de Interfaces Humano Computador

CINAHPA | 2017 - Congresso Internacional de Ambientes Hipermídia para Aprendizagem.

Filmes e períodos históricos selecionados:

a) Tróia

Ano: 2004

Direção: Wolfgang Petersen

Período histórico: Idade Antiga

b) Maria Antonieta

Ano: 2006

Direção: Sofia Coppola

Período histórico: Idade Moderna

c) O Grande Gatsby

Ano: 2013

Direção: Baz Luhrmann

Período histórico: Idade Contemporânea).

Duração: 6 semanas

Com base em Bunchball (2010), McGonigal (2011) e Fardo (2013) foram elencados os elementos e mecânicas a serem utilizados na execução da respectiva fase:

Objetivo: Estimular o espírito investigativo e a construção do conhecimento através da pesquisa de períodos específicos da história. Regras: Os componentes das equipes deverão assistir aos filmes previamente selecionados. Em seguida deverão elaborar um relatório escrito sobre os mesmos, bem como uma pesquisa a respeito de seu período histórico acompanhada de um banco de imagens digitais. Obs. Todos os discentes desenvolverão as atividades propostas para cada um dos filmes e épocas estudadas.

Sistema de feedback: Após a avaliação dos materiais entregues.

Esta atividade será realizada a cada duas semanas.

Pontos: Serão 10 pontos distribuídos ao longo de toda a fase.

Desafios: Assistir aos filmes e elaborar relatórios destacando aspectos relevantes para a produção de moda. Elaborar relatórios de pesquisa de acordo com a época estudada. Montar um banco de imagens digitais de acordo com a época estudada.

Bens Virtuais: Chaves que simbolizam os pontos.

Placar de classificação: Em formato de banner onde serão adicionados os bens virtuais que representam a pontuação obtida ao longo da fase.

Quadro 1: Elementos e mecânicas da fase 1

\subsection{Fase 2:Ferramentas de Trabalho: quem sabe} cria!

Envolverá as atividades de elaboração de um Projeto Criativo de Composição de Imagem de Moda tendo como base filmes de épocas históricas específicas.

O Projeto Criativo de Composição de Imagem de Moda será constituído por: Mapa Mental; Painel 


\section{$16^{\circ}$ ERGODESIGN USIHC CINAHPA}

Iconográfico; Cores Predominantes; Silhuetas; Maquiagens e Cabelos; Geração de alternativas; Seleção de alternativas; Representação gráfica e explicação textual das ideias (esboço); Seleção de looks, cabelo e maquiagem; Seleção de cenário, locação e objetos de cena; Seleção de modelos e poses (expressão corporal).

\section{Duração: 5 semanas}

Seguem os elementos e mecânicas pertinentes à esta fase elaborados com base em Bunchball (2010), McGonigal (2011) e Fardo (2013):

Objetivo: Desenvolver o senso de organização, de planejamento, a
criatividade e o senso crítico diante da elaboração de um projeto de
composição de imagens de moda.
Regras: Os componentes das equipes deverão elaborar um Projeto
Criativo de Composição de Imagem de Moda contendo: Mapa
Mental; Painel Iconográfico; Cores Predominantes; Silhuetas;
Maquiagens e Cabelos; Geração de alternativas; Seleção de
alternativas; Representação gráfica e explicação textual da ideia
(esboço); Seleção de looks, cabelo e maquiagem; Seleção de cenário,
locação e objetos de cena; Seleção de modelos e poses (expressão
corporal).
Obs. Os discentes desenvolverão as atividades propostas somente
para um filme e época, sendo estes definidos previamente mediante
sorteio.
Sistema de feedback: Após a avaliação dos materiais entregues.
Esta atividade será realizada no final da fase 2.
Pontos: Serão 10 pontos distribuídos ao longo de toda a fase.
Desafios: Elaborar um Projeto Criativo de Composição de Imagem
de Moda tendo como base o filme assistido na fase 1, bem como a
pesquisa histórica e o banco de imagens elaborados também na fase
1.
Bens Virtuais: Lâmpadas que simbolizam os pontos.
Placar de classificação: Em formato de banner onde serão
adicionados os bens virtuais que representam a pontuação obtida ao
longo da fase.

Quadro 2: Elementos e mecânicas da fase 2

\subsection{Fase 3: A Jornada: um passo de cada vez}

Envolverá as atividades de execução do Projeto Criativo: Composição de Imagem de Moda tendo como base filmes de épocas históricas específicas.

\section{Duração: 4 semanas}

Seguem os elementos e mecânicas elaborados com base em Bunchball (2010), McGonigal (2011) e Fardo (2013): $16^{\circ}$ Ergodesign - Congresso Internacional de Ergonomia e Usabilidade de Interfaces Humano Tecnológica: Produto, Informações Ambientes Construídos e Transporte

$16^{\circ}$ USIHC - Congresso Internacional de Ergonomia e Usabilidade de Interfaces Humano Computador

CINAHPA | 2017 - Congresso Internacional de Ambientes Hipermídia para Aprendizagem.

Objetivo: Desenvolver o senso de organização, de planejamento, de
trabalho em equipe, o relacionamento interpessoal, a iniciativa, a
criatividade e o senso crítico frente aos desafios da criação de
imagens de moda.
Regras: Os componentes das equipes deverão executar as fotos
tendo como base o Projeto Criativo de Composição de Imagem de
Moda elaborado na fase anterior.Obs. Cada equipe será responsável
pela execução das fotos de acordo com o filme e época pré-definidos.
Entretanto, os demais discentes também participarão dessas
atividades, auxiliando a equipe ao longo da execução das fotos.
Sistema de feedback: Após a avaliação da atividade executada. Esta
atividade será realizada no final da fase 3 .
Pontos: Serão 10 pontos distribuídos ao longo de toda a fase.
Desafios: Executar as fotos tendo como base o Projeto Criativo de
Composição de Imagem de Moda elaborado na fase 2 .
Bens Virtuais: Pegadas que simbolizam os pontos.
Placar de classificação: Em formato de banner onde serão
adicionados os bens virtuais que representam a pontuação obtida ao
longo da fase.

Quadro 3: Elementos e mecânicas da fase 3

Ao longo do semestre estão previstas dois workshops: Expressão Corporal e Técnicas de Penteados e Maquiagem. Durante a execução das fotos os discentes terão auxílio de um profissional da área da beleza para elaborar os cabelos e maquiagens.

\section{Considerações Finais}

Os jogos, que normalmente são vistos como uma forma de lazer, podem se fundir às necessidades atuais em diversos aspectos, como o profissional e o educacional. Dessa forma, a utilização da gamificação pode contribuir para motivar o sujeito durante a realização de tarefas podendo aumentar o engajamento do indivíduo e colaborar com a satisfação, o prazer, a diversão e o interesse. Em relação à metodologia proposta, infere-se que a fase 1 poderá estimular o espírito investigativo e a construção do conhecimento. De modo semelhante, a fase 2 poderá desenvolver o senso de organização, bem como a criatividade e o senso crítico dos discentes. A fase 3 , auxiliará no desenvolvimento do senso de planejamento e o relacionamento interpessoal, essenciais para a formação de um futuro produtor de moda. Essa nova geração de estudantes considera as atividades educacionais ultrapassadas e monótonas, logo, a gamificação da disciplina de Projeto

Interdisciplinar será uma experiência inovadora e poderá ser consolidada como uma nova perspectiva metodológica para o ensino na área da moda. 


\section{Referências Bibliográficas}

ASSMANN, H. Reencantar a educação.

Petrópolis: Vozes, 1998.

BUNCHBALL.COM . Gamification 101: An Introduction to the Use of Game Dynamics to Influence Behavior. 2010. Disponível em: $<$ http://www.bunchball.com/sites/default/files/dow nloads/gamification101.pdf $>$. Acesso em: mar. 2017.

CORTI, Kevin. Games-based Learning: a serious business application. PIXE Learning Limited, 2006. Disponível em http://www.pixelearning.com/docs/seriousgamesbu sinessapplications.pdf $>$. Acesso em: mar. 2017.

FARDO, Marcelo Luis. A gamificação como estratégia pedagógica: estudo de elementos dos games aplicados em processos de ensino e aprendizagem. 2013, 143 f. Dissertação (Mestrado em Educação), Universidade de Caxias do Sul, Caxias do Sul, 2013.

FAZENDA, I. Interdisciplinaridade: um projeto em parceria. São Paulo: Loyola, 1991.

FONTOURA, A. M. A interdisciplinaridade e o ensino do design. Projética Revista Científica de Design v.2, n.2, dez 2011, p.86-95.

HUIZINGA, Johan. Homo Ludens: o jogo como elemento da cultura. Tradução João Paulo Monteiro. 2. ed. São Paulo: Perspectiva, 1990.

INSTITUTO FEDERAL DE EDUCAÇÃO, CIÊNCIA E TECNOLOGIA DO RIO GRANDE DO SUL (IFRS). Projeto Pedagógico do Curso Técnico em Vestuário. Erechim, RS: IFRS, 2016.

\section{INSTITUTO PAULO FREIRE. Inter-} transdisciplinaridade e transdiciplinadidade. Disponível em: $<$ http://www.inclusao.com.br/projeto_textos_4 8.htm>. Acesso em: 10 março. 2017.

JAPIASSU, H. Interdisciplinaridade e patologia $16^{\circ}$ Ergodesign - Congresso Internacional de Ergonomia e Usabilidade de Interfaces Humano Tecnológica: Produto, Informações Ambientes Construídos e Transporte

$16^{\circ}$ USIHC - Congresso Internacional de Ergonomia e Usabilidade de Interfaces Humano Computador

CINAHPA | 2017 - Congresso Internacional de Ambientes Hipermídia para Aprendizagem.

do saber. Rio de Janeiro: Imago, 1976.

KAPP, Karl. The Gamification of Learning and Instruction: Game-Based Methods and Strategies for Training and Education. San Francisco: Pfeiffer, 2012.

LEE, Joey; HAMMER, Jessica. Gamification in Education: What, How, Why Bother? 2011. Disponível em:

$<$ http://www.gamifyingeducation.org/files/LeeHammer-AEQ-2011.pdf>. Acesso em: mar. 2017.

MCGONIGAL, Jane. A Realidade em Jogo: por que os jogos nos tornam melhores e como eles podem mudar o mundo. Tradução de Eduardo Rieche do original Reality is Broken. Rio de Janeiro: Best Seller LTDA, 2012.

MORIN, E. A. Os sete saberes necessários à educação do futuro. São Paulo: Cortez, 2001.

SANTOS, B. S. Pela mão de Alice. São Paulo: Cortez, 1999.

SEIXAS, Luma da Rocha. A efetividade de mecânicas de gamificação sobre o engajamennto de alunos do ensino fundamental. 2014. 135f. Dissertação. (Mestrado em Ciência da Computação). Universidade Federal de Pernambuco, Recife, 2014.

SILVA, Caetana Juracy Resende et al. (Orgs.). Institutos Federais, lei 11.892, de 29/11/2008: comentários e reflexões. Natal: IFRN, 2009.

TONÉIS, Cristiano Natal. A Experiência Matemática no Universo dos Jogos Digitais: $\mathrm{O}$ processo do jogar e o raciocínio lógico e matemático. 2015. 128f. Tese. (Doutorado em Educação Matemática). Universidade Anhanguera, São Paulo, 2015.
Realização:

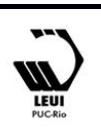

